\title{
A Research On Wind Power Forecasting Techniques
}

\author{
Sanju Saini, Muskaan Ahuja
}

\begin{abstract}
Wind Power forecasting has an important contribution towards power system planning, operation, real time balancing and reliable wind power integration (large scale). Accurate forecasting of wind is of concern due to the uncontrollability and randomness of wind power. Various forecasting models (physical, statistical, historical and intelligent models) associated with wind power and wind speeds are briefly reviewed in this paper. Mainly, this review paper briefly explain the need of wind power/speed forecasting and make a brief review of all techniques used.
\end{abstract}

Keywords: wind power forecasting, Numerical weather prediction, statistical models persistence models, machine learning models, Hybrid models, multistep ahead forecasting.

\section{INTRODUCTION}

Wind energy is a characterized by the lowest cost and the lowest source available[1]. Also, smart grid technology has shown rapid development in many countries. Due to fast changing environment, wind power forecasting (estimate)has become very important. A numbers of authors [2] have concentrated on load forecasting review, while others [3] have focused on electricity price forecasting review. However, this paper briefly reviews of all the wind power forecasting techniques

In order to meet the ever raising power rations, large amount of power is required to be generated in the existing power sector. In recent years, wind power generation of India has shown tremendous increase. In 2011, the potential for wind farms was firstly assessed to more than 2000. At the end of March 2017 the total installed capacity of wind power was $32.17 \mathrm{GW}$ and it was mainly spread across north, south and west region. Main advantages of wind power forecasting are reduction of imbalance charges and penalties. Some authors have already represented reviews on wind power and wind speed forecasting methods [3,5-7]. The wind forecasting techniques are mainly based on physical, statistical and hybrid approaches.

\section{CLASSIFICATION OF WIND FORECASTING TECHNIQUES}

Various methods used for wind forecasting are based on methodology and inputs used. These methods can be classified on the basis of prediction horizons also [7]. A brief discussion on these methods is presented in the following

sub-sections:

Revised Version Manuscript Received on August 19, 2019.

Dr. Sanju Saini, Department of Electrical Engineering, DCRUST, Murthal, Haryana , India. (Email: asanjusaini3669@gmail.com)

Muskaan Ahuja, Department of Electrical Engineering, DCRUST, Murthal, Haryana , India (Email: bMuskaanahuja93@gmail.com)

\section{1 classifications on the basis of prediction}

Immediate or short- term (8hours-ahead) forecasting (For purpose of economic load dispatch planning, load increment/ decrement, wind turbine control)

Short-term (day-ahead) forecasting (For purpose of unit commitment \& generator online/offline decision)

Long-term (multiple-days-ahead) forecast ing

\section{2 classification on the basis of inputs (TABLE 1)}

It is given in following subsections :

\section{2.1 Physical Models}

These are based on the numerical weather prediction. This method is used for long term prediction. It includes persistence forecast and climatology forecast. Third is trend forecast. And the last is analog forecast[8]

\subsubsection{Statistical models}

For statistical model, data (historical) of the Wind Energy Conversion System (WECS) may be used [9]. Following types of statistical model have been proposed:

\subsubsection{Autoregressive (AR) model:}

In the field of signal processing, an Auto Regressive (AR) Model is used to represent the time varying processes. The performance of AR model is enhanced by a number of researchers, to provide higher accuracy.

\subsubsection{Autoregressive moving average (ARMA) models}

Some authors have predicted hourly average (up to 10 hours in advance) of wind speed is by using ARMA \& persistence model. In 2004, Milligan et al. have investigated autoregressive moving average (ARMA) time series model to forecast. Result indicates that $10 \%$ to $20 \%$ improvement is achieved over method of persistence.

\subsubsection{Autoregressive integrated moving average (ARIMA) model}

In 2009, Palomares-Salas et. al. have used an ARIMA model. The ARIMA model has been proved to give better results than ANN model (10 minutes, 1 hour, 2 hour, 4 hours). A modified ARIMA model has been employed for the California Independent system operator (ISO) in 2009 by Y. Makarov et al. 


\subsubsection{Hybridization of NWP and Statistical Methods}

Here, physical \& statistical tools for the selection of inputs have been combined .

\subsubsection{Persistence models}

Persistence model is a very simple method and is used by a number of authors $[10,11]$.

\subsubsection{Machine learning models}

In last three decades, Machine learning Models have become most popular in the forecasting community, e.g., feed-forward neural networks (FFNNs) which are act as a sliding window over the input sequence [12]. Some other neural network models are SVM and Genetic Neural Network (GNN).

An ANN and the linear regression has been proposed for wind speed forecasting by X. Wang et.al. In 2004, a short-term wind power forecasts by using ANN has been proposed by Kariniotakis et. al. Short-term predictions of wind power have been made up to (1-48 hours) ahead. ANN is also utilized to predict day-ahead wind power [11]. In 2007, development of an ANN based wind power prediction system (by K. Methaprayoon et. al.) and its confidence interval (CI) forecast has resulted into an efficient unit commitment (UC) scheduling.

TABLE 1

Factors affecting wind power [7]

\begin{tabular}{|c|c|}
\hline Class & Input variables \\
\hline $\begin{array}{l}\text { Characteristics } \\
\text { of atmosphere }\end{array}$ & $\begin{array}{l}\text { Pressure, cloudiness, rainfall, } \\
\text { temperature, radiations, cloud } \\
\text { cover, density, humidity, } \\
\text { turbulence, stratification, cloud } \\
\text { formation. }\end{array}$ \\
\hline $\begin{array}{l}\text { Characteristics } \\
\text { of topographic }\end{array}$ & $\begin{array}{l}\text { Hub height, turbine size, tower } \\
\text { height, turbine position, elevation }\end{array}$ \\
\hline $\begin{array}{l}\text { Behavior } \\
\text { Indices }\end{array}$ & $\begin{array}{l}\text { Hydrological cycle, cloud radiation } \\
\text { interaction, pressure tendency, } \\
\text { spatial resolution, temporal } \\
\text { behavior, cloud radiation } \\
\text { interaction. }\end{array}$ \\
\hline $\begin{array}{l}\text { Characteristics } \\
\text { of wind power }\end{array}$ & $\begin{array}{l}\text { Spesd, direction, wind power, local } \\
\text { wind profile, radiation } \\
\text { transmission, sir density, history, } \\
\text { sine \& cosine of wind direction. }\end{array}$ \\
\hline $\begin{array}{l}\text { Stochastic } \\
\text { uncertainty }\end{array}$ & $\begin{array}{l}\text { Extreme power system events, } \\
\text { guest wind spead, ocean land } \\
\text { interaction, dynamic performance } \\
\text { of the generator, exchange of } \\
\text { momentum, storms, thunders, risk } \\
\text { index, load distribution among } \\
\text { parallel turbine. }\end{array}$ \\
\hline $\begin{array}{l}\text { Geographical } \\
\text { conditions }\end{array}$ & $\begin{array}{l}\text { Terrain roughness, surface } \\
\text { roughness, soil wetness, air } \\
\text { temperature, obstacles, orography, } \\
\text { geographical height, mean sea level } \\
\text { pressure, atmosphere covering, } \\
\text { snow covering, complex terrain. }\end{array}$ \\
\hline
\end{tabular}

In 2008, short-term wind speed prediction using markov chain approach based on ANN methodology has been proposed by Kani et. al. The Genetic Neural Network (GNN) technique has been proposed in 2010 by X. Weidong et.al. Here 3 hours ahead wind speed is predicted by NN.

In 2001, using the FFNN architecture to predict wind power, four inputs are used for Neural Network by L. Shuhui et. al. FFNN and RNN (Recurrent Neural Network) have been used to forecast daily and monthly wind speed time series (M. C. Deo et.al. in 2003). In the same year, FFNN has been used to predict the average hourly wind speed. In [12], Back Propagation Neural Network (BPNN) has been used. In 2004, wind speed prediction has been made successfully by fuzzy model and wind power in wind parks is calculated by using spatial correlation (Ioannis G. Damousis et. al.)

In 2009, wind speed is forecasted using ANN model, in which number of input layers and output layers is proposed (E. Cadenas et. al.). By the same author, wind speed is forecasted using a hybrid ARIMA with ANN. In 2010, data obtained by decomposing the original wind speed time series is used to train a feedforward neural network. In 2012, univariate as well as multivariate ARIMA is used with RNN (recurrent neural network). Sideratos et al. have predicted the wind power by using on-line as well as off-line strategies in 2012. In 2010, MAPE of $0.189 \%$ has been achieved ( $\mathrm{Li}$ Gong et.al.). Potential of support vector machine is investgated for estimation of wind speed in the years 2004 \& 2008 by Mohandes et.al. \& Sreelakshmi et. al. respectively. .

Liu Da et. al. (2014) have used GA (Genetic Algorithm) fine tuned SVM (support vector machine) in conjunction with Wavelet Transform. Potentials of support vector regression, Recurrent neural networks and Fuzzy-logic based wind prediction models have been investigated to predict up to 3 hours in steps of 15 minutes. ANN+GA+DWT based model is used by Sanju Saini et. al. for wind speed prediction in 2019.

\subsubsection{Hybridization of machine learning models with other models}

The main aim of Hybrid models is to get advantage of each model (used) to achieve a global optimum prediction performance [4]. Zhao et al., in 2012 have given a hybrid method. Catalão et. al. in 2011 proposed a hybrid model using artificial neural network (ANN) with WT (wavelet transform) for wind power forecasting (short-term). In 2012, authors illustrated two different Hybrid models (J. Shi. et.al.).

Hybrid intelligent systems for short term wind power forecasting have been proposed by Z.H. Guo et.al. (2011), M. Negnevitsky et.al. (2006) \& H. Liu et. al. (2010). In 2011, model based on ARIMA and (LS-SVM) has been proposed by H. Jha et.al.. In 2003, NWP input as well as on-line SCADA measurements are used (by P.Pinson et. al.) to predict wind power. In 2006, ANFIS is used to predict the wind vector (2.5 minutes ahead) (By W.C. Potter et.al.). In 2010, a wind power forecasting is done by X. Junrong et.al. using (artificial neural network + fuzzy logic) based method. In [14], three methods are proposed to predict wind speed. In 
[15], artificial intelligent techniques such as ANN algorithm are used for the prediction of wind power. Here four different methods have been used. It has been found that the Genetic algorithm perform better .

ANN is used with (GA+PSO) and Back propagation learning is validated for an actual wind farm by some authors.

\section{MULTI-STEP AHEAD WIND POWER FORECASTING}

It uses present step of prediction for the next step prediction.

\section{DISCUSSION RESULTS ON KEY ISSUES}

This literature survey covers a number of research papers. Each model given by the researchers is having its own characteristics and operates under different situations. Main issues related to wind forecasting can be summarized as follows:

It is observed that NWP model perform better as compared to statistical models.

Selection of the input variables is main issue.

The complexity of artificial neural networks, its overtraining or over fitting may result in increase of prediction error.

The time required for updation of data (for prediction of each step) is an important issue for improvement of short time prediction results.

Due to sudden changes, large swings may occur. Prediction of such types of events is necessary.

\section{CONCLUSION}

The ultimate goal of using various wind power forecasting techniques is to improve the prediction accuracy using various hybrid and intelligent prediction tools. In literature, various models for wind power prediction have been given. As discussed in this paper, each method has its own advantage, disadvantage, its own characteristics and their way of implementation. Prediction accuracy is improved using the latest models but it is not possible to make the exact prediction. However, they have helped to maximize the reliability of wind power obtained from wind farms.

\section{FUTURE SCOPE}

We need to do further research in many areas for better results as follows:

Novel methodologies have to maintain a balance between forecasting accuracy and computation time.

(Physical + statistical) models may be used to improve forecasting results..

The models must be tested on actual wind farms.

Establishment of a Universal Forecasting Error Evaluation System. .

Uncertainties in Wind farms as well as surroundings may be automatically managed by the models.

\section{REFERENCES}

1. Dr. Sanju Saini, Muskaan Ahuja(2017). Wind Speed Prediction Using Wavelet transform and Artificial Neural Network. IJRECE 5 (4), 161-168.
2. Gross, G., and Galiana, F.D.(1987). Short-term load forecasting. Proceedings of the IEEE, 75: 1558-1573.

3. [3] Niimura T.(2006). Forecasting techniques for deregulated electricity market prices: An extended survey. IEEE PES Power System Conference and Exposition, 51-56.

4. Mitchell.M. (2004). An Introduction to Genetic Algorithms, Prentice-Hall of India Private Limited, New Delhi-110001.

5. Xin Zhao, Shuangxin Wang, and Tao Li.(2011). Review of evaluation criteria and main methods of wind power forecasting. Energy Procedia, 12, 761-769.

6. Ernst. B, Oakleaf. , Mark L., Ahlstrom, Lange. M, Corinna Moehrlen, Lange. B, Ulrich Focken, and Kurt Rohrig.(2007). Predicting the wind. IEEE power \& energy magazine, 5, 78-89.

7. Xiaochen W., Guo.P., and Huang. X. (2011). A Review of Wind Power Forecasting Models. ICSGCE 12, 770-778.

8. Rizwan.M., Saini.S., and Singh.U.(2012). Prediction of wind energy using intelligent approaches. IICPE, IEEE 5 th india international conference.

9. National Renewable energy Laboratory [online]Available:

http://www.nrel.gov/wind/integrationdatasets/eastern/dat a.html.

10. Saroha.S., and Aggarwal.S.K.(2015).A Review and Evaluation of Current Wind Prediction Technologies. WSEAS Transaction on Power Systems, 10, 1-12.

11. Sanchez I.(2006). Short-term prediction of wind energy production. International Journal of Forecasting, 22(1), 43-56.

12. Anurag More and M.C. Deo.(2003).Forecasting wind with neural networks, Marine Structures. 16, 35-49.

13. Gong Li and Jing Shi.(2010). On comparing three artificial neural networks for wind speed forecasting. Applied Energy, 87,(7) 2313-20.

14. Hui Liu et al.(2013). Forecasting models for wind speed using wavelet, wavelet packet, time series \& artificial neural networks. 107, 191-208.

15. Balakrishna.C. Moorthy, Agarwal.A. and Deshmukh.M.K. (2015). Artificial Intelligence Technique for Wind Power Prediction: A Case Study. 8(25), 1-10.

16. Dr. Sanju Saini, Muskaan Ahuja (2019). Wind speed prediction using wavelet transform and GA trained Artificial Neural Network. International Conference on Contemporary Engineering, Technology and Management, Shimla. 